\title{
Historical and size-dependent genetic variation in hybrid mussel populations
}

\author{
J. P. A. Gardner and \\ D. O. F. Skibinski
}

Biomedical and Physiological Research Group, School of Biological Sciences, University College of Swansea, Singleton Park, Swansea SA2 8PP, U.K.

Samples from the high and low shore were taken from mussel populations at two localities. Croyde Bay and Whitsand Bay in southwest England, within the zone of hybridisation of Mytilus edulis and Mytilus galloprovincialis, and analysed at five polymorphic allozyme loci.

Strong correlations were observed between shell length and allele frequencies at both localities, with a higher frequency of alleles characterising $\boldsymbol{M}$. galloprovincialis being found in larger mussels. Three hypotheses were considered as explanation of these results (1) differential mortality, (2) differential growth and (3) historical change within the hybrid zone. The last hypothesis was rejected because the pattern of length dependent allozyme variation was similar in samples taken in 1980-81 and 1986-87. The observation of small growth differences between $M$. edulis and $M$. galloprovincialis provided evidence against the second hypothesis. Thus, higher mortality of younger $M$. edulis was favoured as the cause of the length-dependent variation. Wave exposure and sand abrasion experienced by the mussels were thought to be the most likely selective factors.

Strong correlations were also observed in these populations between shell length and allozyme heterozygosity. Analysis of genotype frequencies in small and large size classes of mussels provide evidence of a small added effect of heterozygosity, but no evidence of overdominance.

\section{INTRODUCTION}

Studies of micro-evolution in natural populations are most frequently confined to a relatively short period of time. Investigation of population structure might for example be based on a "snapshot" of gene and genotype frequencies calculated for single samples taken from the populations under study. It is less common to find genetic changes being assessed by repeated samples taken from populations over a period of many years. Yet the investigation of the dynamics of genetic structure is important as it can provide direct evidence of selection pressures or stochastic influences.

The ecological genetics of the blue mussel, Mytilus edulis, is probably the best studied of all marine invertebrates. Research has attempted to explain contemporary macro- and microgeographic allele frequency variation in terms of environmental variables such as temperature and salinity (see Boyer, 1974; Koehn et al., 1976; Moore et al., 1980; Koehn et al., 1984, and references therein) or has involved investigations into the significance of multiple locus heterozygosity upon growth rate and physiological energetics (see Beaumont et al., 1983; Koehn and Gaffney, 1984; Hawkins et al., 1986; Diehl and Koehn, 1985; Mallet et al., 1986; Rodhouse et al., 1986, and references therein). Much research has also focused on systematic problems particularly the relationship between $M$. edulis and its close relative Mytilus galloprovincialis (see Gosling 1984 for a review).

However, fewer studies have investigated temporal changes in allele frequencies in a single mussel population, especially over periods of several years. When such research has been conducted, it has been over short period of time $(<18$ months) and usually then only for a single enzyme locus. For example, Milkman and Koehn (1977) monitored changing allele frequencies over 13 months at a leucine aminopeptidase locus (Lap-1) in a $M$. edulis population from Long Island Sound, New York, and were able to estimate growth rates from such changes. Colgan (1981) observed significant allele frequency differences in a population of the Australian beaked mussel Brachidontes rostratus at a malate dehydrogenase locus ( $M d h-1)$ 
over a period of 12 months. Koehn and Gaffney (1984) and Diehl and Koehn (1985) found significant changes in allele frequencies in newly settled $M$. edulis spat up until the end of their first year in Long Island Sound, but did not attempt to determine if such changes occurred in other cohorts at the same time, or in subsequent years for the same cohort.

M. edulis and $M$. galloprovincialis were first shown to occur sympatrically in the southwest of England by Lewis and Seed (1969) and Seed (1971), differentiation between the two mussel types being based mainly upon morphological, anatomical and physiological features. The hybrid nature of such populations was subsequently confirmed by allozyme studies (Ahmad and Beardmore, 1976) and further research has enabled the effects of gene pool mixing upon allele frequencies and genotype distributions to be estimated (Skibinski et al., 1978a; Skibinski et al., 1978b; Skibinski and Beardmore, 1979).

In S.W. England, sympatric populations of edulis and galloprovincialis exhibit a strong positive correlation between shell length and gene frequencies at three allozyme loci with larger mussels having a higher frequency of alleles which are typically at high frequency in $M$. galloprovincialis (Skibinski, 1983). Assuming that length and age of mussels are correlated, two hypotheses can be advanced to explain the association between gene frequencies and size. Firstly, it could be the result of differential viability of the two mussel types and some indirect evidence was advanced in support of this hypothesis (Skibinski, 1983). Secondly, it could involve competitive exclusion, with edulis individuals gradually replacing galloprovincialis individuals, resulting in an historical change in the allelic composition of the populations. Thirdly (an explanation which does not require that size and age are correlated), galloprovincialis could have on average a faster growth rate or attain a greater maximum size than edulis.

In this paper we describe a recent investigation of size-dependent allele frequency variation in two hybrid mussel populations using five allozyme loci. For two of the loci, data collected in 1980-81 is compared with data collected in 1986-87 allowing assessment of historical change in allele frequencies over a period of six years. As spawning is an annual event, six new generations of mussels will have been added to the two populations in the period since 1980-81. This would provide a sufficient turnover of population numbers for the detection of a change in gene frequencies large enough to cause the length dependent variation. We also report the existence of positive correlations between allozyme heterozygosity and shell length in these hybrid populations. The extent to which this is merely a consequence of the changing frequencies of alleles between size classes or is an added effect of heterozygosity is investigated.

\section{MATERIALS AND METHODS}

Mussels were collected from two high and low shore locations in hybrid edulis/galloprovincialis populations in S.W. England, Croyde Bay in north Devon and Whitsand Bay in south Cornwall, in late 1986 and early 1987. The sampling locations are from here on referred to as CLS, CHS, WLS and WHS, where $\mathrm{C}$ and $\mathrm{W}$ stand for Croyde and Whitsand respectively, and LS and HS for low shore and high shore respectively. Collections were also made from these populations in $1980-81$, but are not differentiated into separate high and low shore samples. Starch gel electrophoresis was employed to study variation at five enzyme systems in the mussels collected in 1986-87. These are aminopeptidase (AP; EC 3.4.1.3), esterase-D (EST-D; EC 3.1.1.1), mannose phosphate isomerase (MPI; EC 5.3.1.8), octopine dehydrogenase (ODH: EC 1.5.1.11) and phosphoglucose isomerase (PGI; EC 5.3.1.9). AP, EST-D, ODH and PGI have been used in earlier studies because of their diagnostic value in distinguishing between M. edulis and M. galloprovincialis (e.g., Skibinski, 1983; Skibinski et al., 1983); MPI has been found to be of diagnostic value more recently. Tissue samples were prepared from hepatopancreas (liver) for all five enzymes. Following dissection, homogenization was carried out in an equal volume of distilled water. After centrifugation at $0^{\circ} \mathrm{C}$ and $3000 \mathrm{rpm}$ for $15 \mathrm{~min}$, the supernatant was used as the enzyme source. AP and PGI were both run on a Tris-maleate $(p \mathrm{H} \mathrm{7.4)}$ buffered gel (Ahmad et al., 1977), whereas EST-D, MPI and ODH were all run on a Tris-citric acid ( $p \mathrm{H} \mathrm{6.9)}$ buffered gel (Grant and Cherry, 1985). The following staining methods were employed: that of Ahmad et al., (1977) for EST-D, Beaumont et al., (1980) for ODH, Skibinski et al., (1983) for AP and PGI, and Grant and Cherry (1985) for MPI. The number of mussels scored per enzyme locus ranged from 158 (MPI at WHS) to 288 (PGI at CLS), with an average of 208 per sample. The total number of enzyme locus genotypes scored was 4159. Samples of mussels obtained in 1980-81 were scored for only two allozyme systems, EST-D and 
$\mathrm{ODH}$, and the total number of enzyme genotypes scored was 3479 . The sample sizes used for comparison of 1980-81 and 1986-87 collections are given in the legends of figs 3 and 4 .

All the loci are multi-allelic and to aid in data analysis compound alleles as described by Skibinski (1983) were employed. At a given locus the compound allele $E$ is obtained by pooling those alleles which are at highest frequency in $M$. edulis and the compound allele $G$ is obtained by pooling those alleles which are at highest frequency in $M$. galloprovincialis. The two compound alleles are not perfectly diagnostic as $G / G$ edulis and $E / E$ galloprovincialis individuals do occur (Skibinski, 1983). Note that individuals designated as $E / E$ or $G / G$ could be either homozygous or heterozygous for specific allozyme alleles, whereas $E / G$ individuals must be heterozygous for allozyme alleles. Shell length was the only morphometric measurement that was made, and the following size categories were used in analysis and graphical representations of the results: $10-14.9 \mathrm{~mm} ; 15-19.9 \mathrm{~mm} ; 20-24.9 \mathrm{~mm}$; $25-29.9 \mathrm{~mm} ; 30-34.9 \mathrm{~mm} ; 35-39.9 \mathrm{~mm}$; $\geqslant 40 \mathrm{~mm}$. The magnitude of the deviation from Hardy-Weinberg expectations was assessed using the statistic $D=\left(H_{\mathrm{o}}-H_{\mathrm{e}}\right) / H_{\mathrm{e}}$ (where $H_{\mathrm{o}}=$ observed number of heterozygotes, and $H_{\mathrm{e}}=$ expected number of heterozygotes) and the goodness of fit to expectation was assessed by chi-squared analysis. Genetic identity has been computed according to the method of Nei (1972).

The relationship between heterozygosity and shell length was analysed in part with the following model. A correlation between size and heterozygosity could occur by differential viability, historical change or differential growth. Irrespective of the cause of the correlation, the allele frequencies in one size class can be related to those in another by transformation parameters. For example, if differential viability is the biological factor responsible, then these parameters would stand for partial fitness coefficients with respect to viability; if differential growth is the cause then the parameters would be a function of growth coefficients. The model may be represented as follows.

Frequency in size class 1 Transformation parameters Frequency in size class 2

Ratio (size 2/size 1)

\begin{tabular}{ccc}
\multicolumn{3}{c}{ Genotype } \\
\hline$E / E$ & $E / G$ & $G / G$ \\
$p$ & $q$ & $r$ \\
$a$ & $b$ & $c$ \\
$a p / T$ & $b q / T$ & $c r / T$ \\
$($ where & $T=a p+b q+c r)$ \\
$A=a / T$ & $B=b / T \quad C=c / T$
\end{tabular}

An added effect of heterozygosity, that is an interaction betwen the two alleles in the heterozygote will occur if the value of $b$ is greater than, or less than, the mid-point between $a$ and $c$. If differential viability is involved this would imply heterosis (as defined by Falconer, 1981) with respect to this component of fitness, but if differential growth is involved this would imply an added effect of heterozygosity on growth rate. An interaction can be estimated by calculating $h(\%)=$ $\{[B-(A+C) / 2] /(|A-C|)\} \times 100$. If $h=0$ then $b=0.5(a+c)$ and there is no added effect of heterozygosity. Two models will be tested. The first, as described above, tests an additive relationship between gene dosage and the transformation parameters. The second tests a multiplicative relationship, for example $a=x^{2}, b=x, c=1$ and may be more realistic biologically. The multiplicative model will also be appropriate in a situation where several rounds of additive transformation occur between the size classes. The model is tested by using $\log A, \log B$ and $\log C$ in place of $A, B$, and $C$ in the equation for $h$. In both models, values of $h$ above 100 per cent would indicate overdominance with respect to growth or viability. Confidence limits of 95 per cent for the values of $h$ have been set using the technique of bootstrapping. The genotype frequencies in the samples of large and small mussels were used to generate random replicate bootstrap samples for which values of $h$ were calculated. The confidence limits of $h$ were found to be almost identical in two replicate sets of 2000 bootstrap samples. Thus, the limits for one of these sets was used.

\section{RESULTS}

For the mussels sampled in 1986-87, it is clear that whilst the mean $E / E$ homozygote frequency over all five loci decreases with increasing shell length, the mean $G / G$ homozygote frequency exhibits an increase in frequency with increasing shell length regardless of position on the shore (fig. 1). The frequency of the $E / G$ heterozygote shows a much less pronounced increase than the $G / G$ homozygote and generally remains intermediate between the frequencies of the $E / E$ and $G / G$ genotypes regardless of shell length. The mean compound allele frequencies also show a pronounced change in frequencies with shell length (fig. 2) which reflects the change in compound genotype frequencies shown in fig. 1. Comparisons between the 1980-81 and 1986-87 data is possible at two loci, Est-D and $O d h$; the results are shown in figs. 3 

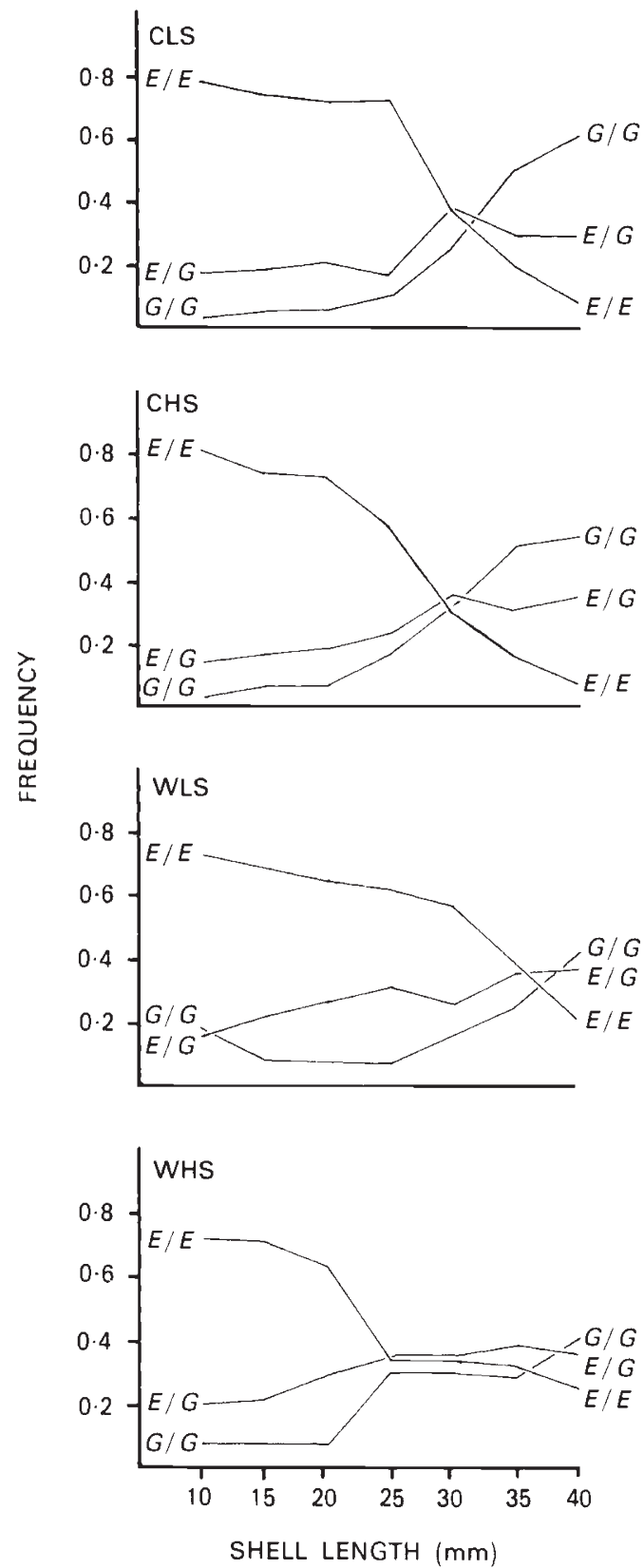

Figure 1 Frequencies of the compound genotypes $E / E, E / G$ and $G / G$ (averaged over five loci) plotted against shell length. For Croyde low shore (CLS), Croyde high shore (CHS), Whitsand low shore (WLS), and Whitsand high shore (WHS).

and 4. On the whole, there appears to be good agreement between the two sets of data. Some idea of the extent of differences expected according to the historical hypothesis may be gauged from fig. 5 which gives growth curves for edulis and gallo. provincialis from S.W. England computed from
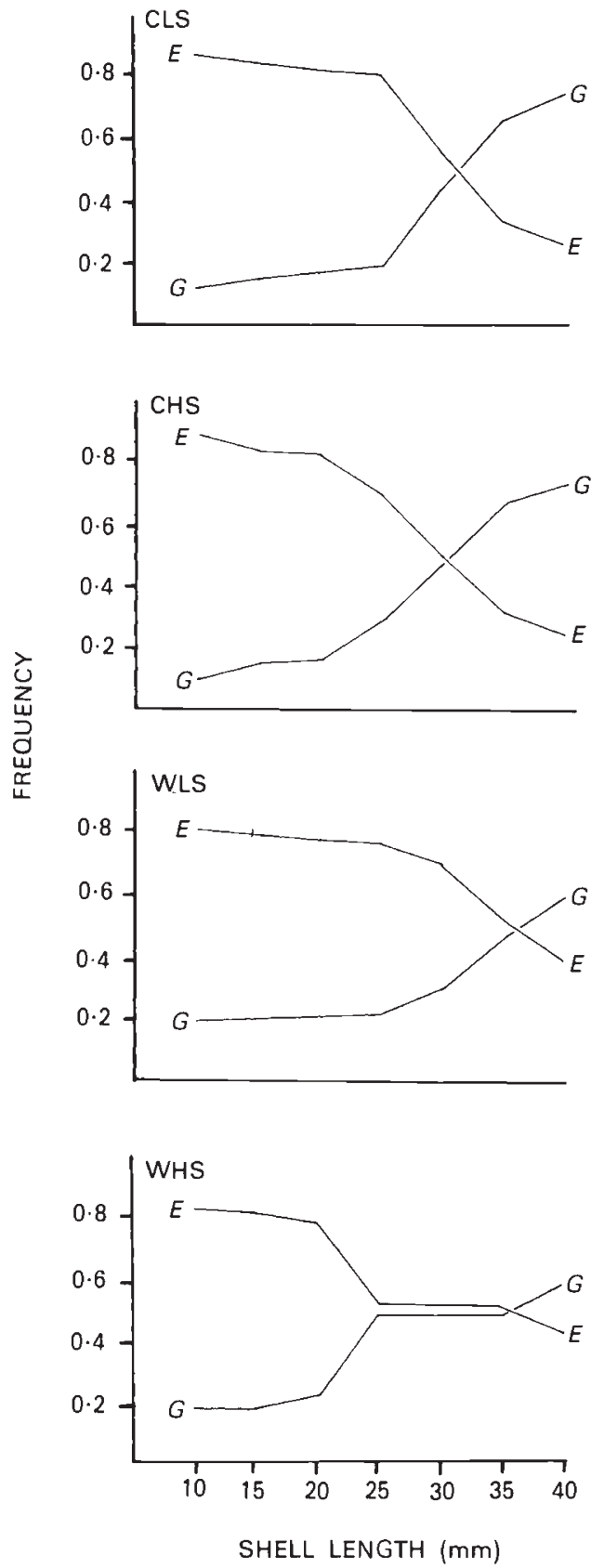

Figure 2 Frequencies of the compound alleles $E$ and $G$ (averaged over five loci) plotted against shell length.

data given by Skibinski (1983). Despite the known variability of molluscan growth rates it is clear from fig. 5 that mussels of the $10-14.9 \mathrm{~mm}$ size class in 1980-81 would have grown to $40 \mathrm{~mm}$ or greater by $1986-87$. Thus, mussels of $\geqq 40 \mathrm{~mm}$ in 1986-87 would be expected to have the same high 

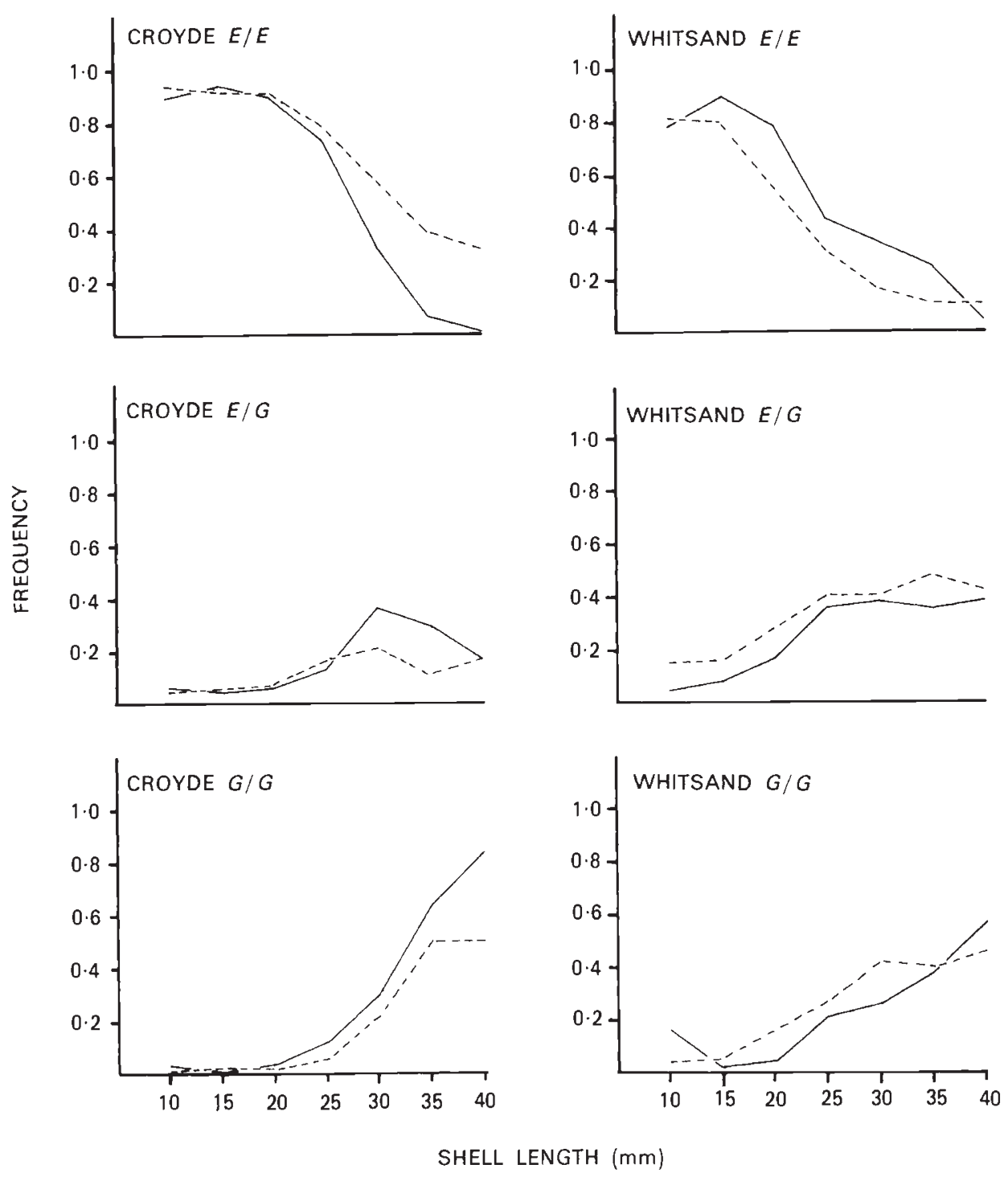

Figure 3 Comparison of the frequencies of three genotypes $(E / E, E / G$, and $G / G)$ at $E s t-D$ in samples of mussels collected in 1980-81 (- - ) and 1986-87 (-) at Croyde and Whitsand. Sample sizes: Croyde 1980-81 (843), Croyde 1986-87 (473), Whitsand 1980-81 (1136), Whitsand 1986-87 (376).

frequency of the $E$ allele as mussels in the 10$14.9 \mathrm{~mm}$ class in $1980-81$. The curves for 1986-87 should be shifted far to the right of the curves for 1980-81. There is no suggestion at all of this for either Croyde or Whitsand from the data in figs. 3 and 4 . Some smaller differences between the two sets do however occur, for example, at Whitsand $E / E$ frequencies are lower and $E / G$ frequencies higher in $1980-81$ for both loci.

The results shown in fig. 2 suggest that the form of the relationship between size and compound allele frequency is sigmoidal, with the maximum gradient at intermediate size classes. This pattern can also be seen for the compound homozygote frequencies (fig. 1). The patterns for compound genotype frequencies (fig. 1) and compound allele frequencies (fig. 2 ) in relation to shell length are similar for CLS, CHS and WLS. By contrast, the patterns for both genotype and allele frequencies at WHS are very different (figs. 1 and 2 ). In particular, the point of most rapid decline in the frequency of $E$ (or increase in $G$ ) at WHS occurs at a much lower shell length than at WLS. The initial $E$ allele frequency (for mussels of $10-$ 

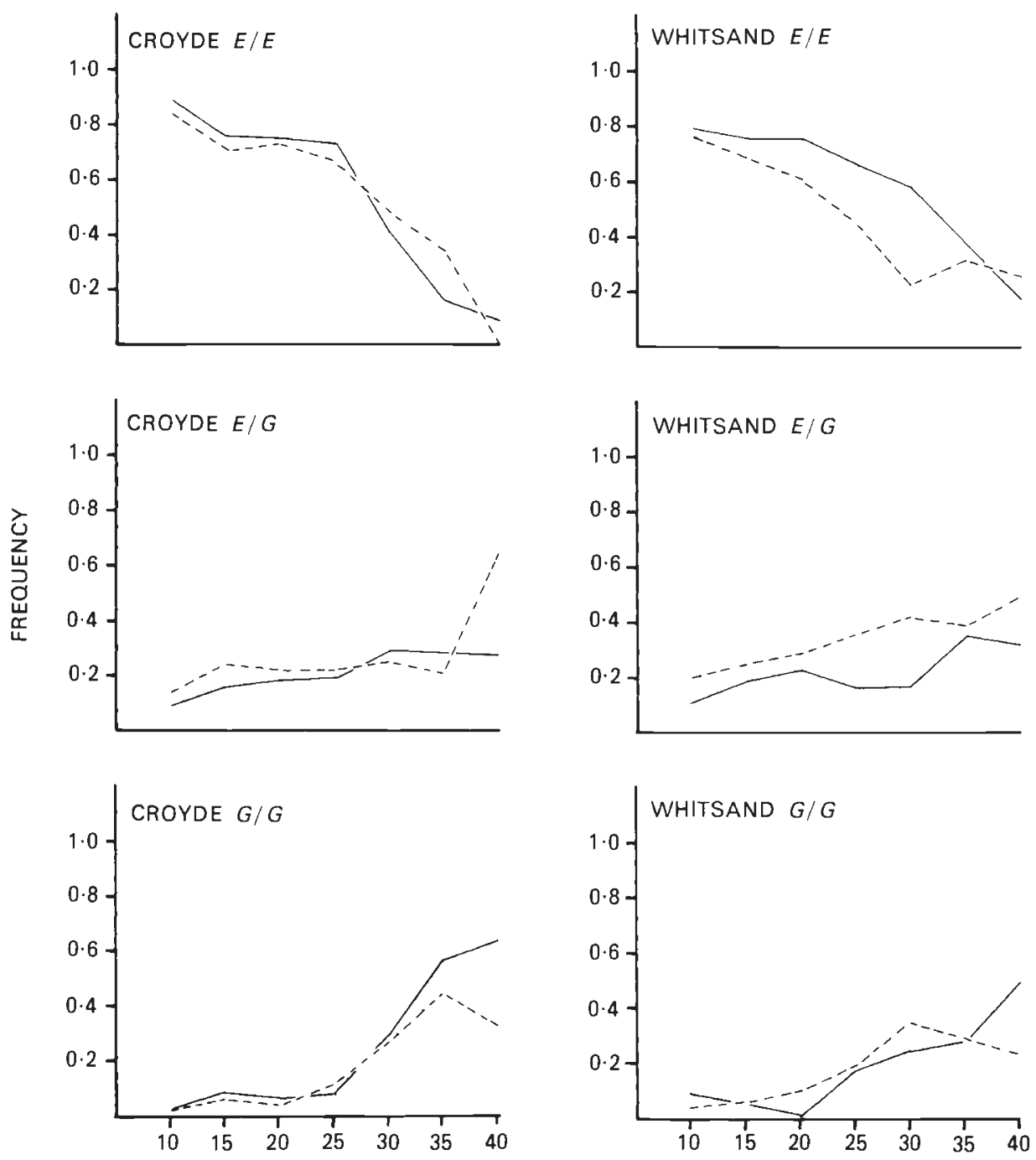

SHELL LENGTH $(\mathrm{mm})$

Figure 4 Comparison of the frequencies of three genotypes $(E / E, E / G$, and $G / G)$ at $O d h$ in samples of mussels collected in 1980-81 (- - ) and 1986-87) (_ ) at Croyde and Whitsand. Sample sizes: Croyde 1980-81 (502), Croyde 1986-87 (438), Whitsand 1980-81 (998), Whitsand 1986-87 (400).

$14.9 \mathrm{~mm})$ at Croyde is approximately 0.9 whereas at Whitsand it is $0 \cdot 8$. Final $E$ allele frequency (that of individuals of $\geqslant 40 \mathrm{~mm}$ length) at Croyde is $0 \cdot 25$, whereas at Whitsand the value is 0.4 . Thus, the overall decrease in $E$ (or increase in $G$ ) appears to be much greater in magnitude at Croyde than at Whitsand. Table 1 shows the results of linear regression analysis of mean compound $E$ allele frequency against length after arcsin transformation of the frequency values, a transformation appropriate for sigmoidal relationships. The differences in initial values of, and rates of decrease of, $E$ with increasing shell length for both Croyde and Whitsand as described above, are reflected in the similarity of intra-site values of the intercepts (Croyde $=88.810 \pm 0.583$ (standard error); Whitsand $=71 \cdot 239 \pm 0 \cdot 144)$ and the gradients $($ Croyde $=-1.719 \pm 0.020 ; \quad$ Whitsand $=-1.063 \pm$ 0.0969).

The length-dependent change in $E$ for each individual locus is shown for each location in fig. 6. It is clear that the greatest rates of decrease in $E$ regardless of location, are exhibited by Est-D, Mpi and Odh. 


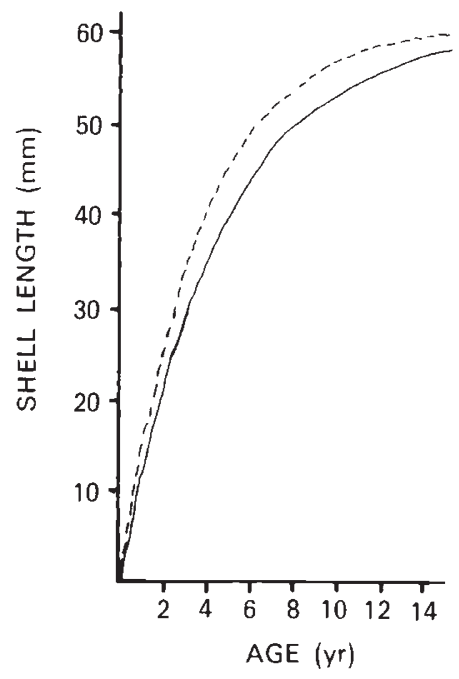

Figure 5 Shell length as a function of age for edulis (and galloprovincialis (---) calculated from the vonBertalanffy growth equation using parameters obtained by Skibinski (1983).

At all four locations, each of four loci, Est-D, $M p i, O d h$, and $P g i$ show very significant $(P<$ $0.001)$ deficits in the numbers of observed heterozygotes from the numbers expected according to Hardy-Weinberg equilibrium. This deficit is to be expected as a result of the pooling of size classes differing in allele frequency. The fifth locus, $A p$, shows statistically significant deficits $(0 \cdot 01>$ $P$ ) at CHS, and at CLS and WHS (both $0.05>P$ ), whilst the $\chi^{2}$ value was not significant $(P>0.5)$ at WHS. The mean $D$ values for each locus, averaged for the four locations, are shown in table 2 with the mean values of intercept and gradient obtained from the linear regression of $E$ allele frequency on shell length. Table 2 also gives values for Nei's genetic identity $(I)$ for the five loci between pure populations of $M$. edulis and $M$. galloprovincialis from S.W. England. There is an obvious inter-
Table 2 Mean values of intercepts and gradients after linear regression of $E$ allele frequency against mid-point of shell length category, and mean $D$ values

\begin{tabular}{lllll}
\hline $\begin{array}{l}\text { Enzyme } \\
\text { locus }\end{array}$ & $\begin{array}{l}\text { Mean } \\
\text { intercept }\end{array}$ & $\begin{array}{l}\text { Mean } \\
\text { gradient }\end{array}$ & Mean $D^{*}$ & $I \dagger$ \\
\hline Ap & 0.923 & -0.008 & -0.1632 & $0.437 \ddagger$ \\
Est-D & 1.379 & -0.027 & -0.5076 & $0.039 \ddagger$ \\
Mpi & 1.263 & -0.022 & -0.4948 & 0.142 \\
Odh & 1.247 & -0.021 & -0.4460 & 0.232 \\
Pgi & 0.923 & -0.014 & -0.2745 & $0.414 \ddagger$ \\
\hline
\end{tabular}

${ }^{*} D=$ deviation of heterozygotes from Hardy-Weinberg equilibrium

$\dagger I=$ genetic identity (Nei, 1972), the extent of genetic differentiation between $M$. edulis and $M$. galloprovincialis. ¥ Data for Skibinski et al. (1980).

relationship between these four statistics. For example, Est- $D$ the most diagnostic locus (as judged by the value of $I$ ) shows the largest deficit of heterozygotes, the most negative gradient and the highest intercept. The pattern of ranking of the five loci is in almost perfect agreement for each of the four statistics. This result suggests that the size dependence is a function of an increasing proportion of the $M$. galloprovincialis genome in larger mussels, rather than a locus specific phenomenon.

The results of regression analysis of heterozygosity on shell length for each of the five allozyme loci and for the mean of the five loci is shown in table 3 . For this analysis the system of compound alleles is not used, that is, allozyme heterozygotes are counted as heterozygotes in the analysis. Similar results are, however, obtained with analysis of compound genotypes. Because these data better describe a linear rather than sigmoidal relationship with shell length, they are untransformed. The value of mean heterozygosity is calculated as the total number of heterozygous individuals for all five loci, divided by the sum of the number of mussels that were typed electrophoretically at each of the five loci. The mean heterozygosity value is

Table 1. Linear regression of mean $E$ compound allele frequency (arcsin transformed) against mid-point of shell length category

\begin{tabular}{lllll}
\hline Location & Intercept & Gradient & $\begin{array}{l}\text { Product moment } \\
\text { correlation coefficient } \\
(r)\end{array}$ & $\begin{array}{l}\text { Significance of } r \\
(5 \mathrm{df})\end{array}$ \\
\hline CLS & 89.394 & -1.698 & -0.943 & $* *$ \\
CHS & 88.227 & -1.739 & -0.977 & $* * *$ \\
WLS & 71.383 & -0.994 & -0.912 & $* *$ \\
WHS & 71.095 & -1.132 & -0.932 & $* *$ \\
\hline
\end{tabular}

Location: $\mathrm{CLS}=$ Croyde low shore; $\mathrm{CHS}=$ Croyde high shore; WLS $=$ Whitsand low shore; WHS $=$ Whitsand high shore.

${ }_{* *}^{*} P<0.01$.

$* * * P<0.001$. 

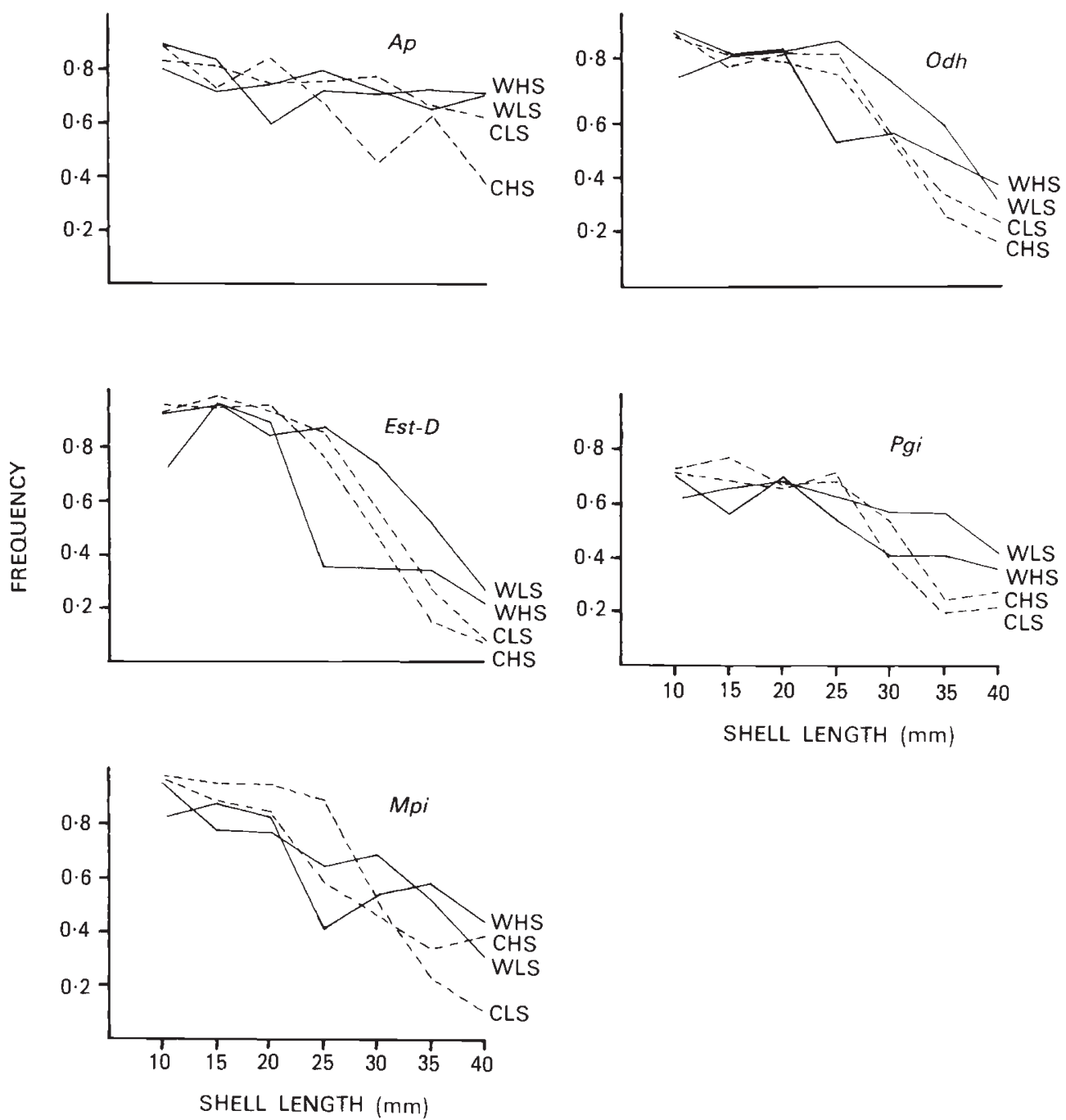

Figure 6 Frequencies of the compound allele $E$, plotted against shell length at four locations for each of five allozyme loci $(A p$, Est-D, Mpi, Odh, Pgi).

strongly and significantly positively correlated with shell length at all four locations. Odh is the only single enzyme locus to be significantly correlated with shell length at all four locations, whereas Pgi is the only enzyme locus that is not significantly correlated at any location. There is a significant positive correlation with shell length for $A p$ and Est-D at three of four locations, and for $M p i$ at two of four locations (table 3 ). The less diagnostic loci $A p$ and $P g i$ have on the whole higher values for the intercept and lower values for the gradient than the more diagnostic loci Est-D, Mpi and Odh. This observation suggests that the increase of heterozygosity with shell length is largely a by product of the change in allele frequencies between size classes rather than the result of an added effect of heterozygosity or of overdominance on growth or viability.

The results of the analysis of the models employing transformation parameters are given in table 4. Values of $h$ have been calculated under the additive and multiplicative models for each locus for Croyde and Whitsand using both 1980-81 and 1986-87 data. In many instances data for the high and low shore samples and from adjacent size classes homogeneous in frequency have been pooled to reduce the confidence limits of $h$. Despite the large confidence limits there are several significant values (instances where the 95 per cent confidence limits do not overlap $h=0$ ) and on the 
Table 3 Heterozygosity as a function of shell length, for each enzyme locus, and for the mean of the five loci

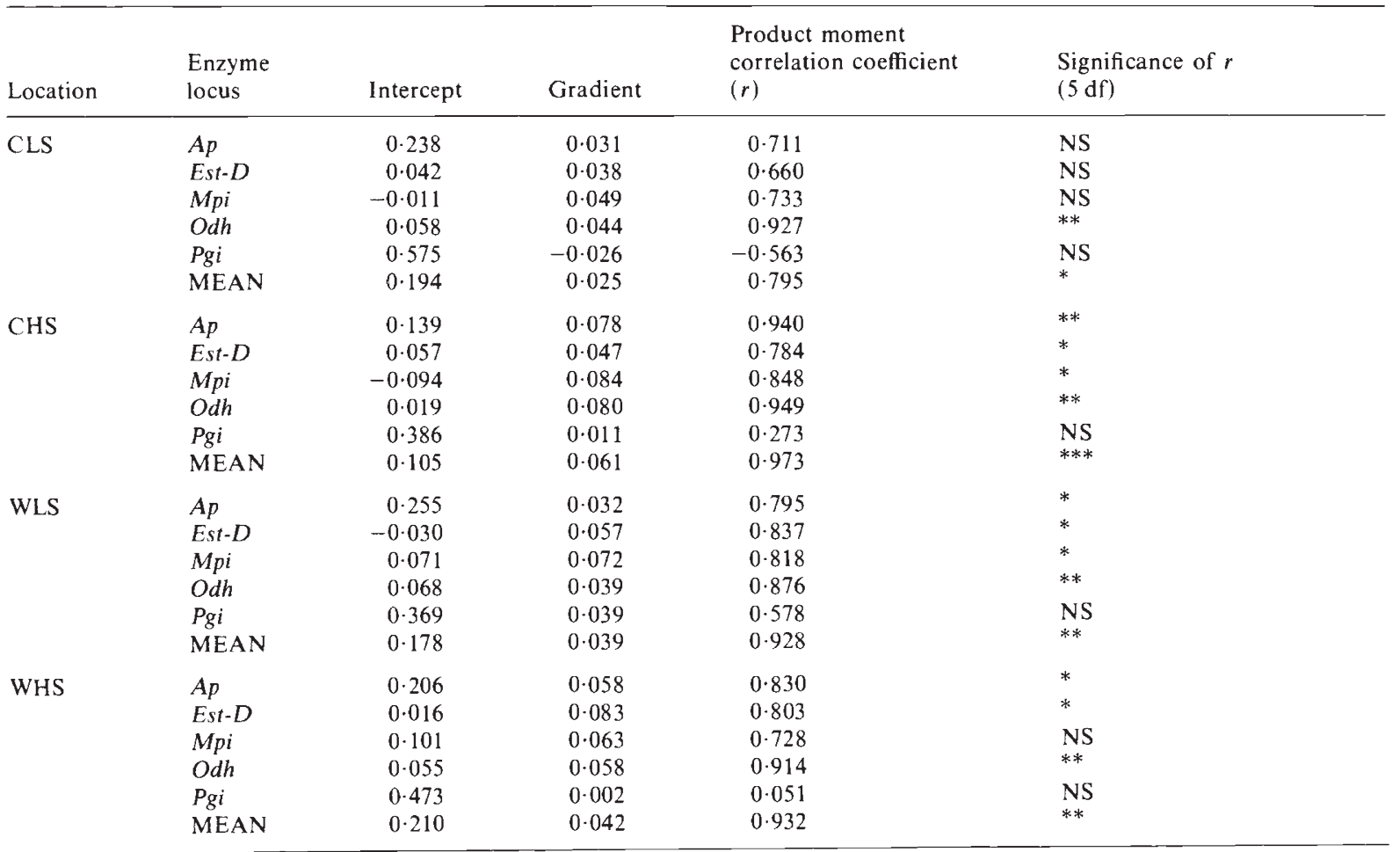

Location: $\mathrm{CLS}=$ Croyde low shore CHS $=$ Croyde high shore; WLS $=$ Whitsand low shore; WHS $=$ Whitsand high shore.

* $P<0.05$.

** $P<0.01$.

$* * * P<0.001$.

Table 4 Values of $h$ with 95 per cent confidence limits under the additive and multiplicative models for Croyde and Whitsand for five allozyme loci

\begin{tabular}{llccll}
\hline & & $\begin{array}{c}\text { Size class } 1 \\
(\mathrm{~mm})\end{array}$ & $\begin{array}{c}\text { Size class } 2 \\
(\mathrm{~mm})\end{array}$ & $\begin{array}{l}h \% \\
\text { (Additive) }\end{array}$ & $\begin{array}{l}h \% \\
\text { (Multiplicative) }\end{array}$ \\
\hline Collection & Est-D & $10-24 \cdot 9$ & $\geqq 35$ & $(-93)-75^{*}(-24)$ & $(6) 38^{*}(67)$ \\
Croyde 1986-87 & Mpi & $10-24 \cdot 9$ & $\geqq 35$ & $(-65)-7(195)$ & $(38) 71^{*}(116)$ \\
Croyde 1986-87 & Odh & $10-29 \cdot 9$ & $\geqq 35$ & $(-95)-83^{*}(-60)$ & $(-30) 1(28)$ \\
Croyde 1986-87 & Pgi & $10-29 \cdot 9$ & $\geqq 35$ & $(-90)-78^{*}(-63)$ & $(-53)-14(14)$ \\
Croyde 1986-87 & Ap & $10-19 \cdot 9$ & $\geqq 35$ & $(-87)-20(449)$ & $(-59) 19(275)$ \\
Croyde 1986-87 & Est-D & $10-24 \cdot 9$ & $\geqq 35$ & $(-99)-96^{*}(-82)$ & $(-80)-40^{*}(-1)$ \\
Croyde 1980-81 & Odh & $10-24 \cdot 9$ & $\geqq 35$ & $(-94)-80^{*}(-49)$ & $(-47)-8(31)$ \\
Croyde 1980-81 & Est-D & $10-24 \cdot 9$ & $\geqq 25$ & $(-84)-48(100)$ & $(0) 49+(100)$ \\
Whitsand (WLS) 1986-87 & Est-D & $10-29 \cdot 9$ & $\geqq 35$ & $(-63) 21(211)$ & $(10) 68^{*}(132)$ \\
Whitsand (WLS) 1986-87 & Mpi & $10-24 \cdot 9$ & $\geqq 35$ & $(-93)-77^{*}(-45)$ & $(-54)-24(13)$ \\
Whitsand 1986-87 & Odh & $10-29 \cdot 9$ & $\geqq 40$ & $(-95)-82 \dagger(0)$ & $(-37) 0(39)$ \\
Whitsand (WLS) 1986-87 & Odh & $10-24 \cdot 9$ & $\geqq 35$ & $(-80)-8(270)$ & $(-25) 43(161)$ \\
Whitsand (WLS) 1986-87 & Pgi & $10-24 \cdot 9$ & $\geqq 40$ & $(-67)-8(123)$ & $(-34) 37(113)$ \\
Whitsand 1986-87 & Ap & $10-19 \cdot 9$ & $\geqq 35$ & $(-57) 401(11969)$ & $(-30) 291(6647)$ \\
Whitsand 1986-87 & Est-D & $10-19 \cdot 9$ & $\geqq 35$ & $(-73)-51^{*}(-21)$ & $(19) 38^{*}(58)$ \\
Whitsand 1980-81 & Odh & $10-24 \cdot 9$ & $\geqq 30$ & $(61)-39^{*}(-11)$ & $(1) 20^{*}(40)$ \\
Whitsand 1980-81 & & & & &
\end{tabular}

$* P<0.05$.

$\dagger$ On borderline of significance at 5 per cent level. Upper and lower 95 per cent confidence limits are given in parentheses. 
whole $h$ values for the test for the additive model tend to be negative whilst those in the test for the multiplicative model tend to be positive though there are some discrepant values.

Two contrasting interpretations are possible. Firstly, the multiplicative model is correct and positive $h$ values suggest a positive added effect of heterozygosity. Secondly, the additive model is correct and there is a negative added effect. The second interpretation is less appealing and it assumes a less realistic biological model.

Interpretation of the results of the models in terms of growth differences is somewhat problematical. This is because a linear relationship between gene dosage and mean growth rate is not necessarily translated into a linear relationship between gene dosage and the transformation parameters calculated from truncated 'slices' from the lower and upper ends of the size distribution. However, the range of the transformation parameters of different genotypes would reflect the ranking of growth coefficients.

It should be noted that with one exception (Whitsand 1986-87, Ap) none of the values of $h$ exceed 100 . There is thus no evidence at all that the observed positive correlation between size and heterozygosity is the result of overdominance with respect to either growth or mortality.

\section{DISCUSSION}

The allele frequencies determined for both Croyde and Whitsand in this study show little change in the period $1980-81$ to $1986-87$. It is clear therefore that the hypothesis of an historical change in allele frequencies occurring within the hybrid mussel populations (Skibinski, 1983) is not correct, as $E / E$ mussels have not replaced, or even begun to replace $E / G$ and $G / G$ mussels within the 6 -year period. There are some smaller differences between the data sets in figs. 3 and 4 which may be too large to be accounted for by sampling variation. These might be explained by variation in the pattern of differential growth or mortality, by microgeographic variation in sampling positions, or by seasonal or annual variation in reproductive performance of the populations. It thus appears that the hypothesis of an historical change can be rejected and that the size-dependent genetic variation is best explained by differential growth or mortality.

For mortality it can be hypothesised that the environment provides a certain carrying capacity for adult mussels and that the galloprovincialis type is at a competitive advantage and fills this niche in a fashion that is largely independent of its frequency in the spat. However, galloprovincialis do not replace edulis either because of the considerable immigration of edulis spat from areas where edulis is in the majority, or because edulis individuals have higher reproductive capacity than galloprovincialis of the same age. Thus, at a given locality such as Croyde or Whitsand it seems possible that a density or frequency dependent competitive advantage of adult galloprovincialis mussels may be balanced either by a reproductive advantage of edulis or by immigration of edulis.

The decrease in $E$ allele frequency as a function of shell length is very similar in both intra- and inter-site comparisons, occurs all over the intertidal distribution of the mussels and is constant from one year to the next. This suggests that the cause is itself relatively constant from year to year and affects all the littoral zone in a similar fashion. It therefore seems possible that a physical factor is responsible for the observed change in allele frequencies, as a physical factor can be widespread in effect and relative constant from year to year and thus be capable of producing the observed changes. In terms of wave action, both Croyde and Whitsand are fairly exposed sites which led Skibinski (1983) to suggest that wave action, as a force of selection, may be acting differentially on the two morphologically distinct forms of mussel. A further possible mechanism of selection is the abrasive effect of very considerable quantities of suspended sand, common to both sites, carried by the incoming tides. The level of sand adjacent to and surrounding the rocks which the mussels inhabit can vary by at least $1 \mathrm{~m}$ from one low tide to the next (personal observation) and it is conceivable that such sand "blasting" at high tide could act differentially upon the different forms of mussel to cause the observed size dependent genetic variation. Further evidence in favour of differential mortality is provided by the results of Gosling and Wilkins (1981) who observed that M. galloprovincialis and hybrid edulis/galloprovincialis mussels are only rarely found in sheltered locations on the coasts of Ireland, whilst these same forms are abundant in more exposed locations. This was confirmed by Skibinski et al., (1983) who demonstrated a significant association at the Est-D locus, of alleles at high frequency in galloprovincialis individuals, with increased exposure at sites in Ireland. Therefore, evidence indicates $M$. galloproviancialis has an advantage in exposed regions. 
At Croyde the high and low shore localities show similar patterns of size dependent variation (figs. 1 and 2) whereas at Whitsand the high and low shore samples show somewhat different patterns. At WHS the frequency of $E / E$ begins to decline sharply at a smaller size than at WLS. This is consistent with more intense selection against the edulis type higher up the shore and suggests that galloprovincialis may better withstand longer periods of emersion than edulis. A similar result was obtained by Skibinski (1983) who observed higher frequencies of $G$ at Est-D for all size classes in mussels sampled higher up the shore.

Studies of hybrid zones using diagnostic allozyme alleles have been made in a number of organisms (e.g., Hunt and Selander, 1973; Blackwell and Bull, 1978). Correlations between allozymes and morphological characters in hybrid zones arise from the strong linkage disequilibrium between the allozyme alleles and alleles at loci controlling the phenotypic differences characterising the hybridising forms. In some instances where mixing of gene pools or introgression is great the disequilibrium is eroded and correlations between the characters disappear (e.g., Avise and Smith, 1974). Previous studies of hybrid populations of edulis and galloprovincialis have demonstrated such correlations among allozymes and morphological characters, the strength of the correlations varying between localities (Skibinski et al., 1978a; Skibinski et al., 1983). In the present study it would thus seem reasonable to suggest that any selective force causing the size dependent pattern of genetic variation acts primarily on alleles which are in disequilibrium with the allozyme alleles and which control the distinctive biological differences between the two forms of mussel. The size dependence effect would be expected to be most apparent for allozyme loci having the greatest diagnostic power as these should show the greatest disequilibrium. This is what is observed; the loci Est-D, $O d h$ and $M p i$ have much lower genetic identity values than $A p$ and $P g i$ and show a more marked decline in frequency with increasing size (fig. 6 and table 2).

The pattern of size dependent variation also differs between the two localities. At Croyde the initial and final frequencies of the $E$ allele have more extreme values than at Whitsand, which results in a faster rate of decline of frequency with size (fig. 2 and table 1). This might also be explained by postulating greater disequilibrium at Croyde than at Whitsand. There is some evidence for this based on correlations between allozyme loci (Skibinski, 1983). Another possibility is that more intense selection is occurring in favour of the galloprovincialis type at Croyde.

The pattern of decrease in the frequency of $E$ (or increase in $G$ ) with increasing shell length is characterised by a sigmoidal relationship (fig. 2). Such a pattern of length-dependent gene frequency variation is typical of that caused by selection against a gene with intermediate dominance (Falconer, 1981). In this situation the change in gene frequency from one size class to the next is smallest at extreme and greatest at intermediate gene frequencies. Thus, the shape of the relationship between size and allele frequency is consistent with the hypothesis of selective mortality.

The observations cited above are, however, also consistent with the hypothesis that the size dependent variation is generated by growth differences caused by the allozyme alleles or by alleles in disequilibrium with them. These observations include the sigmoidal relationship, the differences between sampling localities, the differences between high and low shore, and the differences between allozyme loci. A fairly convincing argument has however been put forward against the growth hypothesis. This is that the growth curves of Fig. 5 indicate that only small differences in maximum length occur between edulis and galloprovincialis. Thus, galloprovincialis would only begin to occur at much higher frequency than edulis in size classes greater than $50 \mathrm{~mm}$, whereas the points of maximum steepness in the observed relationships between size and allele or genotype frequency occur at between 20-35 mm.

It is, of course, possible that both growth and differential mortality are significant factors, as mussels which have greater survival potential may also have an increased growth potential as a result of, for example, lower maintenance costs or increased metabolic efficiency. Further research is at present underway using shell sectioning techniques (for growth rate and age determinations) and growth experiments (both in situ and following transplantation) to attempt to resolve these questions.

Although contradictory results exist, studies of a wide variety of plants and animals provide evidence of positive correlations between growth rate and allozyme heterozygosity (see Mitton and Grant, 1974). Much of this research has been carried out with bivalves (see Gaffney and Scott, 1984; Foltz and Chatry, 1986), though we believe the present study to be the first to be carried out on hybrid molluscan populations. Hybrid populations are of interest for two reasons. Firstly, $E / G$ heterozygotes must be multiply heterozygous at 
very many other loci which control the phenotypic differences between edulis and galloprovincialis. Evidence for this is provided by observations of correlations between genotypes at the diagnostic allozyme loci and the morphological and anatomical characters distinguishing edulis and galloprovincialis, $E / G$ genotypes being morphologically intermediate (Ahmad and Beardmore, 1976; Skibinski et al., 1978a; Skibinski et al., 1978b; Skibinski, 1983). Thus, an added effect of heterozygosity would be accumulated over many loci whether it is the result of dominance or true overdominance at individual loci or due to epistatic interactions between loci. Secondly, if associative overdominance was occurring in the parent populations then there would be no overdominance in the hybrid population when comparing heterozygous with homozygous hybrid genotypes, because of the masking of recessive, deleterious alleles (Zouros and Foltz, 1987). Thus, overdominance or a large added effect of heterozygosity would only be anticipated in the present study because of this first reason. No such thing was found, and it appears that the observed correlation between size and heterozygosity is largely attributable to changing gene frequencies between different size classes.

Acknowledgements The authors gratefully acknowledge the help of Miss Donna Baxter and Mr Eric Roderick in the field and Mrs Cath Fisher and Mrs Mary Warren in the laboratory. This research was supported in part by a NERC studentship to J.P.A.G. and by NERC grant GR3/3988 to D.O.F.S.

\section{REFERENCES}

AHMAD, M. AND BEARDMORE, J. A. 1976. Genetic evidence that the "Padstow Mussel" is Mytilus galloprovincialis. Marine Biology, 35, 139-147.

AHMAD, M., SKIBINSKI, D. O. F. AND BEARDMORE, J. A. 1977. An estimate of the amount of genetic variation in the common mussel Mytilus edulis. Biochemical Genetics, 15, 833-846.

AVISE, J. C. AND SMITH, M. H. 1974. Biochemical genetics of sunfish I. Geographic variation and subspecific intergradation in the bluegill, Lepomis macrochirus. Evolution, 28, 42-56.

BEAUMONT, A. R., BEVERIDGE, C. M. AND BUDD, M. D. 1983. Selection and heterozygosity within single families of the mussel Mytilus edulis (L.). Marine Biology Letters, 4, 151161.

BEAUMONT, A. R., DAY, T. R. AND GADE, G. 1980. Genetic variation at the octopine dehydrogenase locus in the adductor muscle of Cerastoderma edule (L.) and six other bivalve species. Marine Biology Letters, 1, 137-148.

BLACKWELL, J. M. AND BULL, C. M. 1978. A narrow hybrid zone between two Western Australian frog species Ranidella insignifera and $R$. pseudinsignifera: the extent of introgression. Heredity, 40, 14-25.
BOYER, J. F. 1974. Clinal and size-dependent variation at the LAP locus in Mytilus edulis. Biological Bulletin, 147, 535549.

COLGAN, D. J. 1981. Spatial and temporal variation in the genotypic frequencies of the mussel Brachidontes rostratus. Heredity, 46, 197-208.

DIEHL, W. J. AND KOEHN, R. K. 1985. Multiple-locus heterozygosity, mortality and growth in a cohort of Mytilus edulis. Marine Biology, 88, 265-271.

FALCONER, D. S. 1981. Introduction to Quantitative Genetics 2nd edn. Longman, London, $340 \mathrm{pp}$.

FOLTZ, D. W., AND CHATRY, M. 1986. Genetic heterozygosity and growth rate in Louisiana oysters (Crassostrea virginica). Aquaculture, 57, 261-269.

GAFFNEY, P. M., AND SCOTT, T. M. 1984. Genetic heterozygosity and production traits in natural and hatchery populations of bivalves. Aquaculture, 42, 289-302.

GOSLING, E. M. 1984. The systematic status of Mytilus gallo provincialis in western Europe: A review. Malacologia, 25, $551-568$

GOSLING, E. M. AND WILKINS, N. P. 1981. Ecological genetics of the mussels Mytilus edulis and Mytilus galloprovincialis on Irish coasts. Marine Ecology Progress Series, 4, 221-227.

GRANT, W. S. AND CHERRY, M. I. 1985. Mytilus galloprovincialis Lmk in southern Africa. Journal of Experimental Marine Biology and Ecology, 90, 179-191.

HAWKINS, A. J. S., BAYNE, B. L. AND DAY, A. J. 1986. Protein turnover, physiological energetics and heterozygosity in the blue mussel, Mytilus edulis: the basis of variable agespecific growth. Proceedings of the Royal Society, London, Series B, 119, 161-176.

HUNT, W. G. AND SELANDER, R. K. 1973. Biochemical genetics of hybridisation in European house mice (Mus musculus). Heredity, 31, 11-33.

KOEHN, R. K. AND GAFFNEY, P. M. 1984. Genetic heterozygosity and growth rate in Mytilus edulis. Marine Biology, 82 , $1-7$.

KOEHN, R. K., MILKMAN, R. AND Mitton, J. B. 1976. Population genetics of marine pelecypods. IV. Selection, migration and genetic differentiation in the blue mussel Mytilus edulis. Evolution, 30, 2-32.

KOEHN, R. K., HALL, J. G. INNES, D. J. AND ZERA, A. J. 1984. Genetic differentiation of Mytilus edulis in eastern North America. Marine Biology, 79, 117-126.

LEWIS, J. R. AND SEED, R. 1969. Morphological variation in Mytilus from south-west England in relation to the occurrence of Mytilus galloprovincialis (Lmk). Cahiers de biologie marine, 10, 231-253.

MALLET, A. L., ZOUROS, E. GARTNER-KEPAY, K. E. AND FREEMAN, K. R. 1986. Genetics of growth in blue mussels: family and enzyme heterozygosity effects. Marine Biology, 92, 475-482.

MILKMAN, R. AND KOEHN, R. K. 1977. Temporal variation in the relationship between size, numbers, and an allelefrequency in a population of Mytilus edulis. Evolution, 31 , 103-115.

MITTON, J. M. AND GRANT, M. C. 1984. Association among heterozygosity, growth rate and developmental homeostasis. Annual Review of Ecological Systematics, 15, 479499.

MOORE, M. N., KOEHN, R. K. AND BAYNE, B. L. 1980. Leucine aminopeptidase (aminopeptidase-I), $\mathrm{N}$-acetyl- $\beta$ hexoseaminadase and lysomes in the mussel Mytilus edulis L., in response to salinity changes. Journal of Experimental Zoology, 214, 239-249.

NEI, M. 1972. Genetic distance between populations. American Naturalist, 106, 283-292. 
RODHOUSE, P. G., MCDONALD, J. H. NEWELL, R. I. E. AND KOEHN, R. K. 1986. Gamete production, somatic growth and multiple-locus enzyme heterozygosity in Mytilus edulis. Marine Biology, 90, 209-214.

SEED, R. 1971. A physiological and biochemical approach to the taxonomy of Mytilus edulis L. and Mytilus galloprovincialis Lmk from south-west England. Cahiers de biologie marine, 12, 291-322.

SKIBINSKI, D. O. F. 1983. Natural selection in hybrid mussel populations. In Oxford, G. S. and Rollinson, D. (eds) Protein polymorphism: Adaptive and Taxonomic Significance. Systematics Association Special Volume No. 24, Academic Press, London and New York.

SKIBINSKI, D. O. F., AND BEARDMORE, J. A. 1979. A genetic study of intergradation between Mytilus edulis and Mytilus galloprovincialis. Experientia, 35, 1442-1444.

SKIBINSKI, D. O. F., AHMAD, M. AND BEARDMORE, J. A. $1978 a$. Genetic evidence for naturally occurring hybrids between Mytilus edulis and Mytilus galloprovincialis. Evolution, 32, 354-364.
SKIBINSKI, D. O. F., BEARDMORE, J. A. AND AHMAD, M. $1978 b$. Genetic aids to the study of closely related taxa of the genus Mytilus. In Battaglia, B. and Beardmore, J. A. (eds) Marine Organisms: Genetics, Ecology and Evolution, New York and London: Plenum Press, pp. 469-485.

SKIBINSKI, D. O. F., BEARDMORE, J. A. AND CROSS, T. F. 1983. Aspects of the population genetics of Mytilus (Mytilidae: Mollusca) in the British Isles. Biological Journal of the Linnean Society, 19, 137-183.

SKIBINSKI, D. O. F., CROSS, T. F. AND AHMAD, M. 1980. Electrophoretic investigation of systematic relationships in the marine mussels Modiolus modiolus L., Mytilus edulis L., and Mytilus galloprovincialis Lmk. (Mytilidae:Mollusca). Biological Journal of the Linnean Society, 13, 65-73.

ZOUROS, E. AND FOLTZ, D. W. 1987. The use of allelic isozyme variation for the study of heterosis. In Rattazzi, M. C., Scandalios, J. G. and Whitt, G. C. (eds) Isozymes: current topics in biological and medical research, 13, 1-59. 